\title{
Some new records of Selaginella from China
}

\author{
Xian-Chun Zhang
}

\begin{abstract}
Five Asian species of Selaginella distributed in the neighboring regions of China were recently discovered within the territory of China. They are Selaginella pallida Spring, S. pentagona Spring, S. subdiaphana (Wall. ex Hook. \& Grev.) Spring, S. tenuifolia Spring, and S. shakotanensis (Franch. ex H. Takeda) Miyabe \& Kudo. The first four species are mainly distributed in the East Himalaya, while the last one is from Northeast Asia.
\end{abstract}

KEYWORDS: Selaginella, new records, Asia, China

\section{INTRODUCTION}

The initial critical taxonomic revision of Chinese Selaginella was published by Alston (1934), who recognized 41 species from China. In the Chinese National Flora of China and English Flora of China (Zhang 2004, Zhang et al. 2013) the numbers of recognized species increased from 64 and 7 , respectively. Since 2013, we have been engaged in the new international Flora Pan-Himalaya project and carried out several field trips to Yunnan and Xizang, targeting particularly for Selaginella.

Dr. Benito Tan did his master studies on Selaginella from the Philippines and later on mainly on bryophytes. He helped many Chinese plant taxonomists on mosses and ferns and also invited me to the Herbarium of the Singapore Botanic Gardens (SING) to study the Malesian Selaginella when he was the Director. It turned out a report of two additional species to the Flora of Malay Peninsula (Zhang and Tan, 2015).

\section{ENUMERATION OF SPECIES NEW TO THE FLORA OF CHINA:}

Selaginella pallida Spring in Bull. Acad. Roy. Sci. Brussels 10 (1): 234. 1843. Lycopodium tenellum Buch.-Ham., Prodr. FI. Nepal. 18. 1825, nom. illeg., later homonym non (P. Beauv.) Desv. (1814); Selaginella nepalensis Spring, Bull. Acad. Roy. Sci. Brussels 10(1): 234. 1843.

Lycopodium pallidum Hook. \& Grev., Bot. Misc. 2(6): 389. 1831 [ante 10 Sep 1831], nom. illeg., non Lycopodium pallidum Beyr. ex Gaudich. -- Voy. Uranie, Bot. pt. 7: 285.

Institute of Botany, Chinese Academy of Sciences, Beijing 100093

“Corresponding author: zhangxc@ibcas.ac.cn

Date Submitted: 24 January 2018

Date Accepted: 28 March 2018
1828 [16 Aug 1828], nom. illeg.

Selaginella bomiensis Ching \& S.K. Wu, FI. Xizang. 1: 25. 1983.

Representative specimen: China, Xizang, Nyalam, Zhangmu, Friendship Bridge, alt. 1800-2000 m, Xian-Chun Zhang et al. 5298 (PE).

Distribution: Nepal, Bhutan, India, and China (Xizang).

Selaginella pentagona Spring in Mém. Acad. Roy. Sci. Belgique 24: 150. 1849.

Representative specimen: China, Yunnan, Gongshan, alt. 1200-1300 m, Xian-Chun Zhang et al. 8084 (PE); ibid., Xiao-Hua Jin et al., DLJ-ET 0241, DLJ-ET 0251(PE).

Distribution: Myanmar, India, and China (Yunnan).

Selaginella subdiaphana (Wall. ex Hook. \& Grev.) Spring in Bull. Acad. Roy. Sci. Brussels 10(1): 232. 1843.

Lycopodium subdiaphanum Wall. ex Hook. \& Grev. in Hook., Bot. Misc. 2: 401.1831.

Representative specimens: China, Yunnan, Gongshan, alt. 1300-1400 m, Xian-Chun Zhang et al. 8110, 8111 (PE); Xizang, Medog, Xiao-Hua Jin et al. 19130 (PE).

Distribution: Bhutan, Nepal, India, Myanmar and China (Yunnan, Xizang).

Selaginella tenuifolia Sping in Mém. Acad. Roy. Sci. Belgique 24: 253. 1850.

Representative specimen: China, Xizang, Cona, under forest, alt. $2445 \mathrm{~m}$, PE-Xizang Exped. PE6280 (PE).

Distribution: Myanmar, Bhutan, Sikkim, NE India, Nepal, Thailand, and China (Xizang).

Selaginella shakotanensis (Franch. ex H. Takeda) Miyabe \& Kudo, FI. Hokkaido 63. 1930.

Selaginella rupestris (L.) Spring var. shakotanensis Franch. ex H. Takeda in Bot. Mag. Tokyo 23: 237, f. 17. 1909. 
Representative specimen: China, Heilongjiang, Yichun, QiaoPing Xiang and Zhong-Tao Wang 39 (PE).

Distribution: Sakhalin, Japan, Korea, and China (Heilongjiang).

This is a species of the monophyletic group of Selaginella with uniform monomorphic leaves which are found mainly in America. Four species of this group are distributed in China, Selaginella indica (Milde) R.M. Tryon, and S. vardei H. Lev. from Southwest China, while $S$. sibirica (Milde) Hieron., and S. shakotanensis (Franch. ex H. Takeda) Miyabe \& Kudo are from Northeast China.

\section{ACKNOWLEDGMENTS}

This paper is dedicated to the memory of Dr Benito C. Tan who has helped the author in many ways. The author is also thankful to two anonymous reviewers who gave useful comments that improved this manuscript.

\section{LITERATURE CITED}

Alston, A.H.G. 1934. An enumeration of the Chinese species of Selaginella. Bulletin of the Fan Memorial Institute of Biology; Botany. 5: 261-294.

Zhang, X.-C. 2004. Selaginellaceae. Pp. 86-219. In: Zhang X. -C. (ed.), Flora Republica Popularis Sinicae. Vol. 6(3). Beijing: Science Press.

Zhang, X.-C., M. Kato \& H.P. Nooteboom. 2013. Selaginellaceae. Pp. 37-66. In: Wu, Z.Y., Raven, P.H. \& Hong, D.Y. (eds.), Flora of China, vol. 2-3. Beijing: Science Press; St. Louis: Missouri Botanical Garden Press.

Zhang, X.-C and B.C. Tan, 2013. Two new records of Selaginella from Malaysia. Guihaia, 33(5): 588-590. 